\title{
Introduction of lymphadenopathy associated virus or human T lymphotropic virus (LAV/HTLV-III) into the male homosexual community in Amsterdam
}

\author{
R A COUTINHO, * W J A KRONE, $\uparrow$ L SMIT, $\uparrow$ P ALBRECHT-van LENT,* J van der NOORDAA, $\dagger$ \\ W SCHAESBERG, $\ddagger$ AND J GOUDSMIT $†$
}

From the *Municipal Health Service, Department of Infectious Diseases, the $\dagger$ Department of Virology, Academic Medical Centre, and the $\ddagger$ Central Laboratory of the Netherlands Red Cross Blood Transfusion Service, Amsterdam, the Netherlands

SUMMARY To establish when lymphadenopathy associated virus or human T lymphotropic virus (LAV/HTLV-III) was introduced into the Netherlands, we studied a cohort of homosexual men who participated in a hepatitis B vaccine efficacy study between 1980 and 1982 . On entry into the study (November 1980 to December 1981$)$ five $(0.7 \%)$ out of 685 participants were found to have antibodies to LAV/HTLV-III, and during follow up 15 seroconversions were detected among the 680 who had been seronegative initially (end point attack rate $3 \%$ ). LAV/HTLV-III was not transmitted by the heat inactivated hepatitis B virus (HBV) vaccine used. Anal sexual contact and antibodies to cytomegalovirus (CMV) were found to correlate with seropositivity or seroconversion for LAV/HTLV-III. Six out of 15 men who seroconverted reported a mononucleosis like illness, but three of them had other concurrent virus infections. To date, only one of the 20 seropositive men has developed the acquired immune deficiency syndrome (AIDS), three years after his seroconversion. This study shows that the introduction of LAV/HTLV-III into the Dutch male homosexual community took place at the end of the 1970s, a few years before the first case of AIDS in a native Dutchman.

Introduction

Since the acquired immune deficiency syndrome (AIDS) was recognised in the United States of America in 1981, it has spread to Western Europe. The first case of AIDS in the Netherlands was diagnosed in $1982 .^{1}$

AIDS is probably caused by a retrovirus, which was first described by Barré-Sinoussi et al in 1983 as lymphadenopathy associated virus (LAV) ${ }^{2}$ and later by Gallo et al as human T lymphotropic virus type III (HTLV-III). ${ }^{3}$

We investigated the introduction of $\mathrm{LAV} / \mathrm{HTLV}$ III into the Netherlands by studying a cohort of 685 homosexual men who had participated in a hepatitis $B$ vaccine efficacy study (in 1980-2) for the presence of antibodies to LAV/HTLV-III. The primary reason for the study was to rule out the possible transmission of LAV/HTLV-III by the hepatitis B vaccine, derived from heat inactivated plasma.

Address for reprints: Dr R A Coutinho, Municipal Health Service, PO Box 20244, 1000 HE Amsterdam, the Netherlands

Accepted for publication 21 July 1985
Patients, materials, and methods

\section{STUDY POPULATION}

The study population consisted of homosexual men who participated in a placebo controlled efficacy trial of a heat inactivated hepatitis $B$ vaccine. ${ }^{4}$ The plasma used for the preparation of this vaccine was collected before 1977 from unpaid blood donors who were hepatitis B surface antigen (HBsAg) positive. The vaccine trial started in November 1980, participants could enter it until 31 December 1981, and follow up continued until the end of 1982 . Subjects entered the trial if they were aged between 16 and 50 years, were negative for hepatitis $B$ virus markers, had a serum alanine transferase activity of less than 50 IU/1 (normal activity less than $21 \mathrm{IU} / 1$ ), had no serious illness, and had had at least two different male sexual partners in the six months before the intake. For the LAV/HTLV-III study we selected men from the vaccine study who lived in and around Amsterdam.

CONDUCT OF THE STUDY

At entry into the vaccine study (month 0 ) the participants were asked some questions concerning 
their medical history and lifestyle. Age was recorded in years at the time of this interview. The duration of homosexual activity was defined as the number of years from the first homosexual contact until the interview. Each person was asked to estimate the number of different sexual partners in the six months preceding the interview. We did not differentiate between active and passive anal sexual intercourse.

We collected blood at monthly intervals during the first five months and every three months thereafter. During these visits we asked the participants whether they had had any symptoms during the preceding period.

The first and the last blood samples of the participants were tested for the presence of antibodies to LAV/HTLV-III (anti-LAV/HTLV-III). if seroconversion was found, all intervening serum samples were tested under code for anti-LAV/HTLVIII. A participant was considered to have acquired a new LAV/HTLV-III infection if his seroconversion to anti-LAV/HTLV-III was confirmed by at least two sequential blood samples and by western blotting.

\section{LABORATORY METHODS}

The method used to measure antibodies to LAV/HTLV-III is described elsewhere. (Krone WJA et al, submitted for publication). Briefly, enzyme linked immunosorbent assay (ELISA) microtitre plates coated with cell lysates of $\mathrm{H} 9$ cells or with $\mathrm{H} 9$ cells infected with HTLV-III (kindly provided by R C Gallo) were incubated with serum diluted 1:400. The wells were then washed, and appropriately diluted goat anti-human IgG immunoglobulins conjugated to horseradish peroxidase were added. HTLV-III specific immunoglobulins were visualised using 0 phenylene diamine as substrate. All seropostive results were confirmed by an ELISA using purified virus for the coating (Vironostica, Organon, Oss, the Netherlands). Western blotting experiments were carried out as follows. Heat denatured purified virus was subjected to sodium dodecyl sulphate polyacrylamide gel electrophoresis. Proteins were then transferred to nitrocellulose paper, and the paper strips were incubated with a 1:100 dilution of the serum to be tested. The strips were washed and then incubated with biotinylated goat anti-human immunoglobulins (Vector Laboratories, Burlingame, United States of America) and with a complex of avidin and biotinylated horseradish peroxidase. After further washing, serum specific protein bands were visualised using 4-chloro-1-naphtal as substrate.

Tests for the presence of hepatitis B markers were performed by radioimmunoassay (Abbot Laboratories, Chicago, USA), and antibodies to $\mathrm{HBs} \mathrm{Ag}$ expressed as IU/1. Antibodies to hepatitis A virus were measured by an ELISA (Organon), and antibodies to cytomegalovirus (CMV) by complement fixation using $\mathrm{AD} 169$ as the antigen.

\section{STATISTICAL METHODS}

We used an actuarial method to calculate the life table attack rate. The association between potential risk factors and seropositivity or seroconversion for LAV/HTLV-III was studied by stepwise logistic regression, as described previously. ${ }^{5}$

\section{Results}

\section{CHARACTERISTICS OF THE PARTICIPANTS}

Table I shows the characteristics of the 685 homosexual men who participated in this study. Their mean (SD) age was 30.1 (7) years and the mean duration of their homosexual activity 11 (7) years, 240 $(35 \%)$ had had more than 10 different sexual partners in the six preceding months, $128(18.7 \%)$ had a history of syphilis, and $506(73.9 \%)$ of anal sexual contact (active or passive was not specified). On entry to the study, none of the 685 men had antibodies to HBV $(339(49.5 \%)$ had received hepatitis B vaccine, and 346 (50.5\%) placebo), 281 (41\%) had antibodies to HAV, and $486(71 \%)$ had antibodies to CMV. In previous studies the end point attack rate for $\mathrm{HBV}$ was $18.3 \%$ in men receiving placebo, ${ }^{4}$ for $\mathrm{HAV}$ was $14 \%$ in susceptible men, ${ }^{5}$ and for CMV was $27 \cdot 3 \%$ in seronegative men. ${ }^{6}$

TABLE Characteristics of 685 homosexual men participating in the LAV/HTLV-III study

$\begin{array}{ll}\begin{array}{l}\text { Mean (SD) age (years) } \\ \text { Mean (SD) duration of homosexual }\end{array} & 30 \cdot 1(7 \cdot 0) \\ \quad \begin{array}{l}\text { activity (years) } \\ \text { No (\%) with >10 different sexual partners }\end{array} & 11 \cdot 0(7 \cdot 0) \\ \quad \text { in preceding } 6 \text { months } & 240(35 \cdot 0) \\ \text { No (\%) with history of syphilis } & 128(18 \cdot 7) \\ \text { No (\%) who had had anal sexual contact } & 506(73 \cdot 9) \\ \text { No (\%) with hepatitis A antibodies } & 281(41) \\ \text { No (\%) with cytomegalovirus antibodies } & 486(71)\end{array}$

LAV/HTLV-III INFECTIONS AMONG THE PARTICIPANTS On entry into the study (November 1980 to December 1981) five $(0.7 \%)$ out of 685 participants were found to have antibodies to LAV/HTLV-III. During the follow up a total of 15 seroconversions were found among the 680 seronegative men, the end point attack rate over 24 months being 3\%. Figure 1 shows representative serum recognition patterns of LAV/HTLV-III proteins. None of the 15 seroconversions occurred in 1980 , three in 1981 , and 12 in 1982. The slope of the life table attack rate curve (fig 2) also shows that most of the LAV/HTLV-III infections occurred in the second half of the study period. 


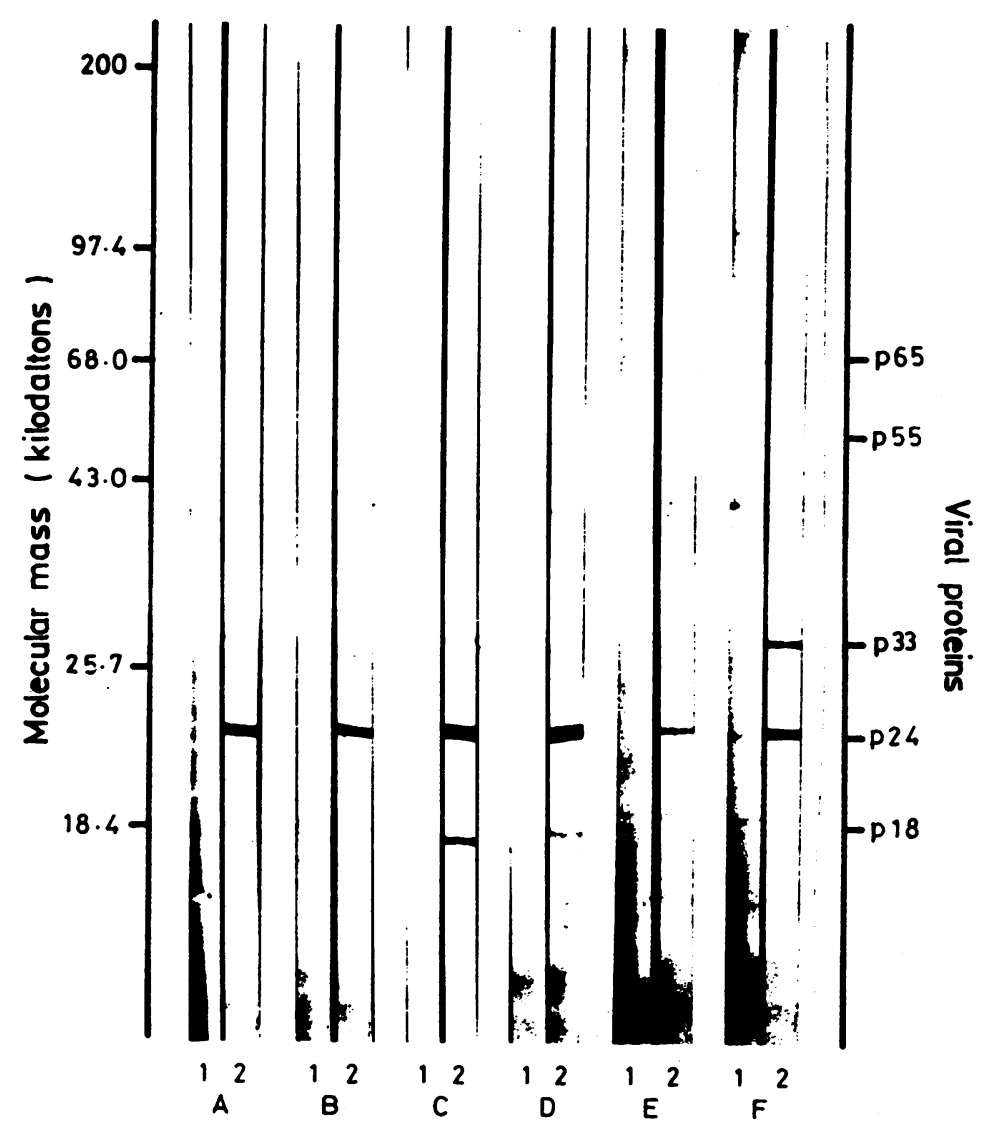

FIG 1 Representative protein recognition patterns of serum samples taken at beginning (1) and end (2) of observation period. $A$ to $E$ are from patients who had seroconersions, $F$ is from a patient who was seropostivie initially. Gag gene products ( $p$ 18, $p$ 24, and $p 55)$ are recognised more prominently, whereas other viral proteins are recognised only weakly.

No entering interval

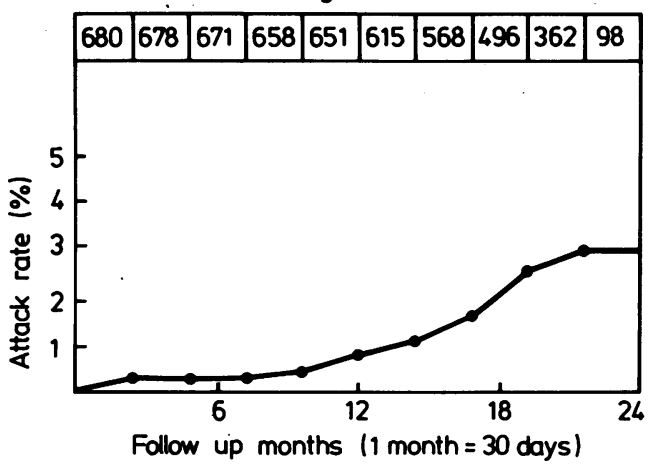

FIG 2 LAV/HTLV-III life table showing attack rate among 685 susceptible homosexual men (1980-2).
ASSOCIATION BETWEEN SEROPOSITIVITY OR SEROCONVERSION FOR LAV/HTLV-III AND POTENTIAL RISK FACTORS

Among the $680 \mathrm{LAV} / \mathrm{HTLV}$-III seronegative men, 336 received hepatitis $B$ vaccine and 344 placebo. Seroconversions occurred in seven $(2 \cdot 1 \%)$ of those receiving vaccine and in eight $(2 \cdot 3 \%)$ of those receiving placebo, not a significant difference.

Seven characteristics (oral sexual contact, antibodies to hepatitis A virus, history of syphilis, age, duration of homosexual activity, number of different sexual partners, and anal sexual contact) were entered in the stepwise logistic regression model to see whether any of these characteristics correlated with seropositivity or seroconversion for LAV/HTLV-III. Anal sexual contact was the only characteristic found to have a significant influence $(p=0.03$; one sided $)$. of the participants who had had anal intercourse, $4 \cdot 1 \%$ were seropositive or seroconverted for LAV/HTLV- 
III, while among those who did not have anal intercourse this percentage was $0.6 \%$ (relative risk according to logistic regression model $2 \cdot 5$ ).

Of the 20 participants with antibodies to LAV/HTLV-III, 19 (95\%) also had antibodies to CMV, whereas of the 665 men with no antibodies to LAV/HTLV-III, $469(70.5 \%)$ had antibodies to CMV, a significant difference $\left(X^{2}=4.54 ; 0.05>p>0.02\right)$.

\section{CLINICAL SYMPTOMS OF LAV/HTLV-III INFECTIONS}

Six of 15 men who seroconverted reported a mononucleosis like illness with malaise and fever, sometimes combined with lymphadenopathy, sore throat, and cough. Two of these six men gave positive results for HBsAg in the same period as the LAV/HTLV-III seroconversion, whereas another participant had had a preceding reinfection with CMV.

\section{CONCURRENT VIRUS INFECTIONS}

Among the 20 seropositive or seroconverted participants, several infections with other virusus were identified. Three men had hepatitis B (two of them in the same period as the LAV/HTLV-III seroconversion), one had a primary CMV-infection, two had a recurrent $C M V$-infection, and one a hepatitis A virus infection. None of these infections appeared to be significantly associated with LAV/HTLV-III (seropositivity or seroconversion).

FOLLOW UP OF MEN WITH ANTIBODIES TO HTLV-III The hepatitis B vaccine trial ended in December 1982 and, though several participants returned several times for the control of their anti-HBs status, no active follow up was performed. We therefore do not have complete and accurate information about all 20 men who were seropositive or who seroconverted during the study period. The following data are available. All doctors who notified (anonymously) patients with AIDS to the chief health inspector in the Netherlands were contacted by telephone and the nature of the present study was explained to them. Each agreed to give the name and date of birth of their patients with AIDS.

To date one patient with AIDS has been identified among the 20 men. Figure 3 summarises the relevant data about this patient. He was found to have seroconverted on 14 April 1981, aged 37. During this period blood samples had been taken every month, so that the seroconversion date is quite accurate. During the period of the seroconversion, he had had fever and fatigue of several days' duration, from which he recovered completely. He remained completely healthy until August 1983, when he developed fever, malaise, diarrhoea, cough, and weight loss. In March 1984 Pneumocystis carinii pneumonia (PCP) and AIDS was diagnosed. He died in January 1985.

Of the remaining 19 seropositive men, seven have spontaneously entered our new prospective study of AIDS among homosexual men, which started in October 1984. All these men are to date in good health, and only one of them has an abnormal T4/T8 ratio (because of a decreased number of T4 cells). One additional person was seen at the university clinic of Amsterdam in November 1984. Tuberculous pleuritis was diagnosed and treated with antituberculous chemotherapy. During 1984 this man had herpes zoster, erythema nodosum, and condylomata accuminata. He responded to his treatment and his immunological status is normal.

\section{Discussion}

During the intake period of the study (November 1980

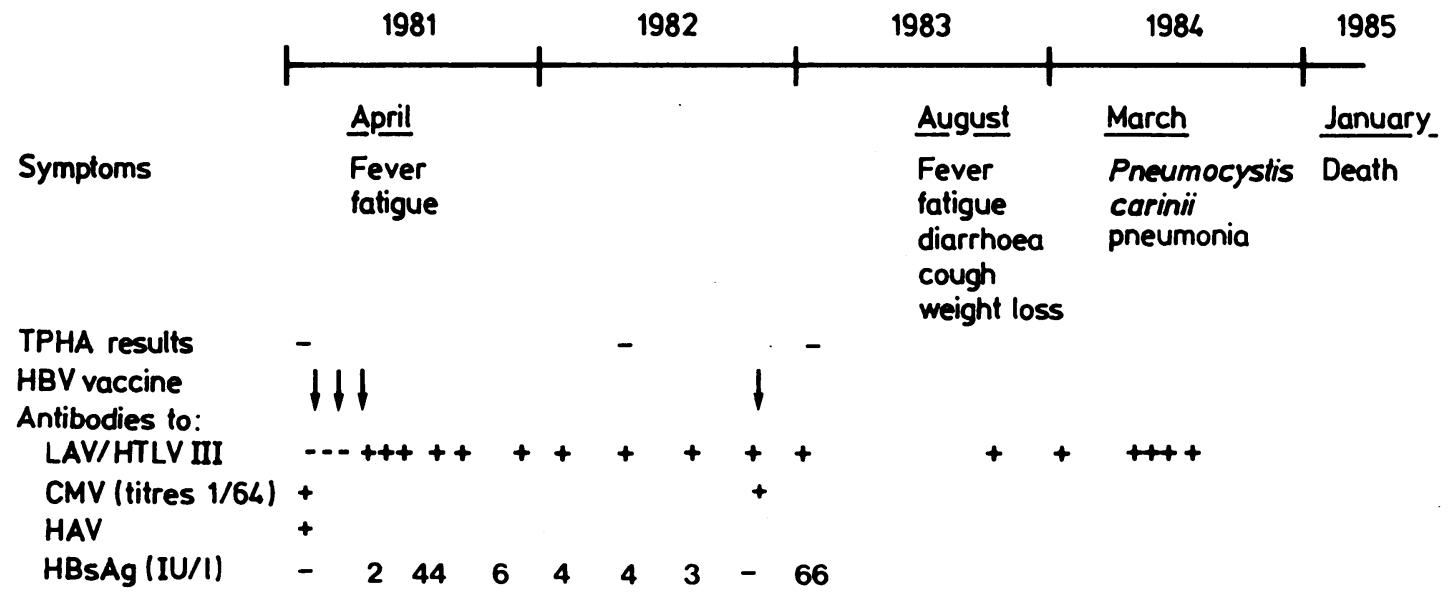

FIG 3 Clinical and laboratory data of a man who became seropositive for LAV-HTLV-III and subsequently developed the acquired immune deficiency syndrome $(-=$ negative, $+=$ positive, results). 
to December 1981) only five $(0.7 \%)$ of the 685 homosexual men participating were found to have antibodies to LAV/HTLV-III; an additional 15 seronegative men seroconverted during follow up, most of them in 1982. The participants, though all hepatitis B marker negative, were at high risk of contracting sexually transmitted disease as is clear from the high attack rates for hepatitis B (18.3\%), hepatitis A (14\%), and CMV (17.3\%) among susceptible men.

From these data it can therefore be concluded that LAV/HTLV-III was introduced as a new virus to the male homosexual community in and around Amsterdam at the end of the 'seventies. This is confirmed by the fact that the first diagnosis of AIDS in the Netherlandds (in a homosexual man) was made in the first half of 1982. These data also lend epidemiological support to the available evidence that $\mathrm{LAV} / \mathrm{HTLV}$-III is the cause of AIDS.

Since 1982, LAV/HTLV-III has spread considerably through the homosexual community in and around Amsterdam. Of 315 homosexual men who entered a prospective study of AIDS between October 1984 and January 1985, 112 (36\%) were found to be seropositive for LAV/HTLV-III.

There has been concern about the possible transmission of AIDS by the plasma derived hepatitis B vaccines. Many of the HBsAg positive carriers from whose plasma these vaccines were prepared were homosexual men, and therefore at $r{ }^{\circ} \mathrm{gh}$ risk of AIDS. The plasma used for the preparation of the heat inactivated (at $103^{\circ} \mathrm{C}$ for 90 seconds and $65^{\circ} \mathrm{C}$ for 10 hours) HBV vaccine used in this study, was collected before 1977, before LAV/HTLV-III was introduced into the homosexual community in the Netherlands, according to this study. The plasma pool was therefore unlikely to have contained LAV/HTLVIII. Moreover, heat has been shown to inactivate LAV/HTLV-III completely. ${ }^{7}$ The study published here proves that the HBV vaccine used did not transmit LAV/HTLV-III, as the percentage of seroconversions among the vaccine recipients $(2 \cdot 1 \%)$ was found to be the same as in those receiving placebos $(2 \cdot 3 \%)$.

Of the lifestyle characteristics of the homosexual men participating in this study, only anal sexual contact appeared to be correlated with seropositivity or seroconversion for LAV/HTLV-III, as was also found in a recent Danish study. ${ }^{8}$ Anal sexual contact is a well known risk factor for two other sexually transmitted diseases in homosexual men: hepatitis $\mathrm{B}^{910}$ and CMV. ${ }^{6} \mathrm{LAV} / \mathrm{HTLV}$-III has been found in semen, ${ }^{11}{ }^{12}$ and entrance of the virus is likely to be facilitated by damage to the mucosa, which is known to occur during anal sexual intercourse. The correlation between antibodies to $\mathrm{CMV}$ and to LAV/HTLV-III also points to the importance of anal sexual contact in transmission. As the number of seropositive men in this analysis was small compared with the number of seropositive men, the influence of other factors in the transmission of LAV/HTLV-III cannot be ruled out.

In a recent article Cooper et al described a mononucleosis like illness in 11 of 12 homosexual men who underwent LAV-HTLV-III seroconversion. ${ }^{13}$ This does not correspond with the findings of our study, in which only a minority of men who seroconverted mentioned any symptoms and some of the men with symptoms had double infections, which made it impossible to identify the cause of the clinical signs. A reason for the discrepancy could be that patients in the Australian study (who were seen every six months) were interviewed again after the seroconversion was detected. The knowledge of the seroconversion may have biased the interviewers, as nothing is mentioned about control retrospective interviews of subjects without a seroconversion. An alternative explanation is that in our study the participants (who were seen at least every three months) simply forgot to mention their symptoms, which may have been of short duration and of minor importance.

From the clinical data we conclude that the incubation period of AIDS in homosexual men can be at least three years after servoconversion, and that during that period most people do not have any clinical symptoms.

In conclusion, our study shows clearly that the introduction of LAV/HTLV-III in the Dutch male homosexual community took place at the end of the 'seventies, a few years before the first diagnosis of AIDS in a native Dutchman, which supports the existing evidence that LAV-HTLV-III is the cause of AIDS.

We thank A J Rijsdijk for statistical help, S A Danner and J Lange for clinical data, W G van Aken and H G Ross for critical comment, and W Maruanaya for typing the manuscript.

This study was supported by the Netherlands Foundation for preventive medicine, grant No 28-1026.

\section{References}

1. Prummel MF, Berge R J M ten, Barrowclough H, Cejka V. Kaposisarcoom en dodelijke opportunistische infekties bij een homoseksuele man met een deficiënt immuunapparaat. Ned Tijdschr Geneeskd 1983;127:820-4.

2. Barré-Sinoussi F, Chermann J C, Rey F, et al. Isolation of a Tlymphotropic retrovirus from a patient at risk for acquired immune deficiency syndrome (AIDS). Science 1983;220:868-71.

3. Gallo RC, Salahuddin SZ, Popovic M, et al. Frequent detection and isolation of cytopathic retroviruses (HTLV-III) from patients with AIDS and at risk for AIDS. Science 1984;224:5003.

4. Coutinho RA, Lelie N, Albrecht-van Lent P et al. Efficacy of a heat inactivated hepatitis $B$ vaccine in male homosexuals outcome of a placebo controlled double blind trial. Br Med J 1983;286:1305-8. 
5. Coutinho R A, Albrecht-van Lent $P$, Lelie $N$, Nagelkerke $N$, Kuipers H, Rijsdijk T. Prevalence and incidence of hepatitis A among male homosexuals. $\mathrm{Br}$ Med $J$ 1983;287:1743-5.

6. Coutinho R A, Wertheim-van Dillen P, Albrecht-van Lent P, et al. Infection with cytomegalovirus in homosexual men. British Journal of Venereal Diseases 1984;60:249-52.

7. Spire B, Dormont D, Barré-Sinoussi F, Montagnier L Chermann J C. Inactivation of lymphadenopathy-associated virus by heat, gamma rays and ultra-violet light. Lance 1985; i:188-9.

8. Melbye M, Biggar R J, Ebbesen P, et al. Seroepidemiology of HTLV-III antibody in Danish homosexual men: prevalence, transmission, and disease outcome. $\mathrm{Br}$ Med $J$ 1984;289:573-5.

9. Szmuness W, Much M I, Prince A M, et al. On the role of sexual behaviour in the spread of hepatitis B infection. Ann Intern Med 1975;83:489-95.

10. Schreeder M T, Thompson S E, Hadler S C, et al. Hepatitis B in homosexual men: prevalence of infection and factors related to transmission. J Infect Dis 1982;146:7-15.

11. Zagury D, Bernard J, Leibowitch, et al. HTLV-III in cells cultured from semen of two patients with AIDS. Science 1984;226:449-51.

12. Ho D D, Schooley R T, Rota T R, et al. HTLV-III in the semen and blood of a healthy homosexual man. Science 1984;226:451-

13. Cooper D A, Gold J, Maclean, P et al. Acute AIDS retrovirus infection: definition of a clinical illness associated with seroconversion. Lancet 1985; i:537-40. 